\title{
CYP26B1 Plays a Major Role in the Regulation of All-trans-Retinoic Acid Metabolism and Signaling in Human Aortic Smooth Muscle Cells
}

\author{
Pauline Ajok Ocaya ${ }^{a, d}$ Ali Ateia Elmabsout ${ }^{a}$ Peder Stefan Olofsson ${ }^{b, e}$ \\ Hans Törmäc Andreas Carl Gidlöf ${ }^{b}$ Allan Sirsjöa \\ a Division of Biomedicine, Department of Clinical Medicine, Örebro University, Örebro, ${ }^{\mathrm{b}}$ Center for Molecular \\ Medicine, Department of Anesthesiology and Intensive Care Medicine, Karolinska University Hospital, \\ Karolinska Institutet, Stockholm, and 'Department of Medical Sciences/Dermatology, Uppsala University, Uppsala, \\ Sweden; ${ }^{\mathrm{d}}$ Department of Cell and Developmental Biology, Weill Medical College of Cornell University, and \\ 'Laboratory of Biomedical Science, The Feinstein Institute for Medical Research, North Shore-LIJ Health System, \\ Manhasset, New York, N.Y., USA
}

\section{Key Words}

Retinoids · CYP26 enzyme family • Vascular smooth muscle cells · All-trans-retinoic acid catabolism • R115866 CYP26 inhibitor

\begin{abstract}
Aim: The cytochrome P450 enzymes of the CYP26 family are involved in the catabolism of the biologically active retinoid all-trans-retinoic acid (atRA). Since it is possible that an increased local CYP26 activity would reduce the effects of retinoids in vascular injury, we investigated the role of CYP26 in the regulation of atRA levels in human aortic smooth muscle cells (AOSMCs). Methods: The expression of CYP26 was investigated in cultured AOSMCs using real-time PCR. The metabolism of atRA was analyzed by high-performance liquid chromatography, and the inhibitor R115866 or small interfering RNA (siRNA) was used to suppress CYP26 activity/expression. Results: AOSMCs expressed CYP26B1 constitutively and atRA exposure augmented CYP26B1 mRNA levels. Silencing of the CYP26B1 gene expression or reduction of CYP26B1 enzymatic activity by using siRNA or the inhibitor R115866, respectively, increased atRA-mediated signaling and resulted in decreased cell proliferation. The CYP26 in-
\end{abstract}

\section{KARGER}

Fax +41613061234 E-Mail karger@karger.ch www.karger.com

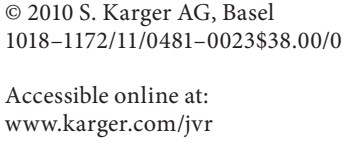

hibitor also induced expression of atRA-responsive genes. Therefore, atRA-induced CYP26 expression accelerated atRA inactivation in AOSMCs, giving rise to an atRA-CYP26 feedback loop. Inhibition of this loop with a CYP26 inhibitor increased retinoid signaling. Conclusion: The results suggest that CYP26 inhibitors may be a therapeutic alternative to exogenous retinoid administration.

Copyright $\odot 2010$ S. Karger AG, Basel

\section{Introduction}

Retinoids play important roles in embryonic vasculogenesis [1] and maintenance of adult tissue by transcriptional regulation [2] of many cellular processes including cell differentiation [3] and apoptosis [4]. Inappropriate retinoid levels during embryonic development result in severe malformations [5]. As demonstrated by Lai et al. [1], retinoids are required for formation of the vascular plexus and remodeling of the plexus into a complete circulatory network.

Changes in proliferation and differentiation of smooth muscle cells (SMCs) have been implicated in the pathogenesis of vascular diseases, including atherosclerosis

Tel. +46 19301 025, Fax +4619303 778, E-Mail allan.sirsjo@ikm.oru.se 
and restenosis [6]. Dramatic effects of retinoids on intimal thickening have been demonstrated in various models of vessel injury [7, 8]. All-trans-retinoic acid (atRA) inhibits neointimal formation in a rat carotid artery injury model $[7,9,10]$, through a process that involves retinoic acid receptor (RAR) signaling [9]. Lee et al. [11] showed that atRA not only inhibited neointimal growth, but also accelerated re-endothelialization of the rat aorta after balloon injury. In atherosclerotic rabbit models, atRA inhibited neointimal formation [8] and the outward remodeling of the vessel after balloon angioplasty [12]. Our previous studies suggest involvement of retinoids in the pathogenesis of atherosclerosis and restenosis $[9,13]$, and recently Takeda et al. [14] demonstrated that retinoids inhibit development of atherosclerosis in apolipoprotein-E-deficient mice.

Retinoids exert their activities by acting as ligands for two families of ligand-activated nuclear receptors, RARs and retinoid X receptors (RXRs). RARs and RXRs can form a heterodimeric complex, which binds retinoic acid response elements (RAREs). Additionally, RXRs also function as homodimers that bind retinoid $\mathrm{X}$ response elements. The biosynthesis of atRA is complex and involves several families of enzymes including retinoid dehydrogenases, as well as retinoid-binding proteins (cellular retinol-binding proteins and cellular retinoicacid-binding proteins), which convert all-trans-retinol (atROH) into all-trans-retinaldehyde and finally to the biologically active atRA [15].

The main pathway of atRA metabolism starts with hydroxylation at the $\mathrm{C} 4$ position of the cyclohexenyl ring [16]. Although many microsomal cytochrome P450 enzymes may initiate atRA metabolism through 4-hydroxylation, their specificity is generally low [17-19]. In contrast, CYP26, a family of cy tochrome P450 enzymes, have a higher specificity for atRA, and convert atRA into 4-hydroxyretinoic acid, 4-oxoretinoic acid and 18-hydroxyretinoic acid [20-22]. The CYP26 group consists of 3 members: CYP26A1, CYP26B1 and CYP26C1. CYP26A1 and $\mathrm{B} 1$ have a high specificity for atRA, while CYP26C1 effectively metabolizes both atRA and 9-cis-retinoic acid [20-22]. Overexpression of CYP26 results in increased atRA clearance [20], and treatment with atRA in vivo has been shown to induce CYP26A1 expression [23], probably due to activation of a RARE located in the CYP26A1 promoter. This feedback loop, where atRA induces its metabolism, suggests that increased CYP26 expression may decrease the effectiveness of atRA in disease therapy $[24,25]$. Inhibition of CYP26 has been shown to increase the levels of endogenous atRA in vivo [26], which further demonstrates the importance of CYP26 in the modulation of retinoid levels.

We previously demonstrated that CYP26 is expressed by rat intimal SMCs and that inhibition of CYP26 results in increased retinoid availability and increased retinoid signaling [27]. This finding suggests CYP26 inhibition as a new potential therapeutic approach for regulating endogenous retinoid levels in human vascular pathology. In light of this, we aimed to investigate the effect and importance of the CYP26 family in human aortic smooth muscle cells (AOSMCs).

\section{Materials and Methods}

\section{Chemicals and Reagents}

atROH and atRA (Sigma Aldrich, St. Louis, USA) were dissolved and diluted in dimethylsulfoxide (DMSO) and handled in a light-restricted regime. Tritium-labeled retinol $\left(\left[{ }^{3} \mathrm{H}\right] \mathrm{ROH}\right)$ and retinoic acid $\left(\left[{ }^{3} \mathrm{H}\right] \mathrm{RA}\right)$ were purchased from Perkin-Elmer Life and Analytical Sciences (Boston, Mass., USA). [methyl- $\left.{ }^{3} \mathrm{H}\right]$ Thymidine was purchased from Amersham Biosciences Europe GmbH (Freiburg, Germany). The CD3106 RAR antagonist was a generous gift from Galderma R\&D (Sofia Antipolis, France). The CYP26 inhibitor R115866 was generously supplied by Dr. Jean Van Wauwe (Janssen Pharmaceutica, Beerse, Belgium). The plasmids, pRARE-TA-SEAP (secreted alkaline phosphatase), pSEAPBasic and pMet-luciferase control were purchased from Clontech (Mountain View, Calif., USA). Small interfering (siRNA) targeting CYP26B1, RNA-interference-negative controls and the Lipofectamine ${ }^{\mathrm{TM}}$ transfection reagents were obtained from Invitrogen (Paisley, UK).

\section{Cell Culture}

Human AOSMCs were purchased at passage 2 from Cambrex Bio Science (Walkersville, Md., USA) and maintained in recommended growth medium (CC-3182 Bulletkit, Cambrex). Cells from passages 5-10 were used for the experiments.

Confluent AOSMCs cultured in 6-well plates were exposed to atRA at different concentrations, the CYP26 inhibitor R115866 at $1 \mu \mathrm{mol} / \mathrm{l}$ or vehicle alone (DMSO) for different periods. All cells were cultured in medium supplemented with atROH $(1 \mu \mathrm{mol} / \mathrm{l})$, except in experimental settings containing atRA. The compounds were added to cells either alone or in different combinations as detailed in the Results section.

\section{Transfection and CYP26B1 Knockdown}

AOSMCs were seeded in 24 -well plates $\left(5 \times 10^{4}\right.$ cells/well $)$ in antibiotic-free medium. At $75-85 \%$ confluence, cells were transfected with plasmids and siRNA. Transfection was done using the Lipofectamine ${ }^{\mathrm{TM}} 2000$ method according to the manufacturer's instructions. Transfection solutions were prepared by mixing $1.5 \mu \mathrm{l}$ of Lipofectamine 2000 with $50 \mu \mathrm{l}$ of Opti-MEM, and by diluting $300 \mathrm{ng}$ of pRARE-TA-SEAP or pSEAP-Basic combined with $20 \mathrm{ng}$ of pMet-luciferase and $7 \mathrm{pmol} / \mu \mathrm{l}$ of RNA-interference-negative controls or siRNA targeting CYP26B1 (sequence: UUGGAGAAGACCUUGCGCUUGUUGC) in $50 \mu \mathrm{l}$ of Opti-MEM. 
$100 \mu \mathrm{l}$ of plasmids/siRNA-Lipofectamine 2000 complexes were added to cells in fresh Opti-MEM. The transfection medium was replaced by growth medium $8 \mathrm{~h}$ after transfection. Then, $24 \mathrm{~h}$ after transfection, cells were exposed to $1 \mu \mathrm{mol} / \mathrm{l}$ of atRA or vehicle alone (DMSO). After $24 \mathrm{~h}$ of atRA stimulation, cells lysates were collected, and the knockdown efficiency of CYP26B1 was determined by reverse transcription polymerase chain reaction (RT-PCR).

\section{Secreted Alkaline Phosphatase and Luciferase Reporter Gene}

Assay

The measurement of secreted alkaline phosphatase activity in the supernatant of cultured transfected cells was done using the secreted alkaline phosphatase Reporter Gene Assay Chemiluminescent kit (Roche Diagnostics Scandinavia AB, Bromma, Sweden) according to the manufacturer's instruction. Conditioned media collected $24 \mathrm{~h}$ after atRA exposure were centrifuged, diluted and incubated for $30 \mathrm{~min}$ at $65^{\circ} \mathrm{C}$. Samples were spun down for $30 \mathrm{~s}$ at $14,000 \mathrm{rpm}$, recovered and mixed with inactivation buffer. After a 5-min incubation, substrate buffer was added and samples reincubated for $10 \mathrm{~min}$. Samples were analyzed by using a luminometer.

Detection of luciferase activity (positive control) in all samples was performed using the Ready-to-Glow Secreted Luciferase Reporter Assay kit (Clontech) according to the manufacturer's instructions. Conditioned media were collected after $24 \mathrm{~h}$ of atRA stimulation and mixed with $5 \mu \mathrm{l}$ of substrate buffer and then immediately analyzed by using a luminometer.

\section{Gene Expression}

Total RNA from AOSMCs was isolated using the EZNA Total RNA kit (Omega Bio-tek, Doraville, Ga., USA) according to the manufacturer's protocol. RNA was then reverse-transcribed to cDNA using random hexamers and Superscript II reverse transcriptase (Invitrogen, Stockholm, Sweden). mRNA levels were determined by RT-PCR in a Taqman universal PCR master mix, using Assay-on-Demand ${ }^{\mathrm{TM}}$ reagents (Applied Biosystems, Foster City, Calif., USA) for human CYP26A1, CYP26B1, CYP26C1 and retinoic acid receptor $\beta$ (RAR- $\beta$ ), and the following primers and probe for $\beta$-actin: forward, 5-CTG GCT GCT GAC CGA GG-3; reverse, 5-GAA GGT CTC AAA CAT GAT CTG GGT-3, and probe, 5-CCT GAA CCC CAA GGC CAA CCG-3. Each sample was analyzed in duplicates using an ABI Prism 7700 Sequence Detector (Applied Biosystems), and the threshold cycle values were correlated to a standard curve. The resulting mRNA levels were normalized to $\beta$-actin.

\section{Retinoid Uptake and Metabolism}

AOSMCs were cultured in the recommended growth medium in $60-\mathrm{mm}$ dishes until confluence. Four hours prior to retinoid incubation, the growth medium was changed. Cells were then exposed to R115866 (1 $\mu \mathrm{mol} / \mathrm{l})$ or vehicle alone (DMSO). $\left[{ }^{3} \mathrm{H}\right] \mathrm{ROH}$ or $\left[{ }^{3} \mathrm{H}\right] \mathrm{RA}(1.0 \mu \mathrm{Ci} / \mathrm{ml}$ medium) was added to triplicate cultures for 6 or 24 h. Cell-associated radioactivity was separated by highperformance liquid chromatography following sample hydrolysis and extraction [28]. Tritium activity was normalized to the amount of protein in the extract (as determined by the biuret assay).

\section{$\left[{ }^{3} \mathrm{H}\right]$ Thymidine Incorporation and Cell Proliferation}

AOSMCs were seeded in 24 -well plates $\left(10^{4}\right.$ cells/well $)$ and maintained for $24 \mathrm{~h}$. Cells were then exposed to different concen-

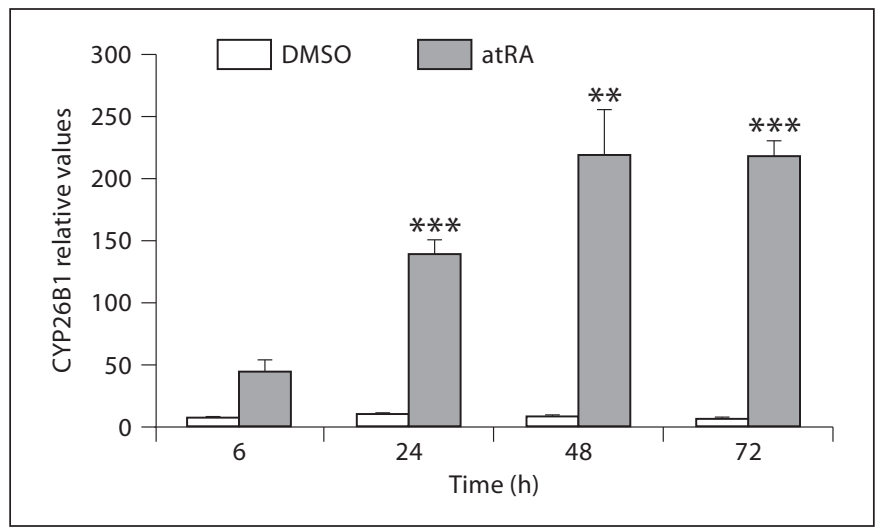

Fig. 1. atRA-induced CYP26B1 mRNA expression in AOSMCs. mRNA expression of CYP26B1 in AOSMCs after treatment with $1.0 \mu \mathrm{mol} / \mathrm{l}$ atRA for 6-72 h. Levels were normalized to the expression of $\beta$-actin. Bars and whiskers show means $\pm \mathrm{SEM}, \mathrm{n}=4 .{ }^{* *} \mathrm{p}$ $<0.01,{ }^{* * *} \mathrm{p}<0.001$ versus control (Student's $\mathrm{t}$ test).

trations of atRA or the pan-RAR antagonist CD3106 (1 $\mu \mathrm{mol} / \mathrm{l})$ in the presence or absence of R115866, or to different concentrations of R115866 in medium supplemented with $1 \mu \mathrm{mol} / \mathrm{l}$ atROH (except in experimental settings containing atRA or CD3106). $\left[{ }^{3} \mathrm{H}\right]$ Thymidine $(1 \mu \mathrm{Ci} /$ well $)$ was added to cells $24 \mathrm{~h}$ prior to harvest. Cells were then harvested and lysed, and incorporated radioactivity was quantified using a liquid scintillation counter as previously described [28].

For evaluation of proliferation, AOSMCs $\left(2 \times 10^{4}\right.$ cells/well $)$ were plated in 12-well plates and maintained for $24 \mathrm{~h}$ in the recommended growth medium. Cells were then exposed to R115866 (5 $\mu \mathrm{mol} / \mathrm{l})$ in medium supplemented with atROH $(1 \mu \mathrm{mol} / \mathrm{l})$ and after $72 \mathrm{~h}$ trypsinized and counted in Bürker chambers. Results are expressed as the ratio of counted to seeded cells.

\section{Statistical Analysis}

Results were analyzed using the two-tailed Student's t test or one-way analysis of variance (ANOVA) with Dunnett's or Bonferroni's adjustment for multiple comparisons as indicated in the figure legends. $\mathrm{p}<0.05$ was considered significant. Values are presented as means \pm SEM. The results from the DNA synthesis assay were fitted to a 4-parameter logistic equation by nonlinear regression using the Graph Pad Prism software (Graph Pad Prism 4, San Diego, Calif., USA) to calculate $\mathrm{IC}_{50}$ values.

\section{Results}

\section{CYP26B1 Expression in AOSMCs}

Real-time RT-PCR was used to study the expression of CYP26 enzymes in AOSMCs. Stimulation of AOSMCs with $1 \mu \mathrm{mol} / \mathrm{l}$ atRA for a period of 6-72 $\mathrm{h}$ induced CYP26B1 mRNA in a time-dependent manner (fig. 1). CYP26A1 and CYP26C1 were barely detectable in 
Fig. 2. Effects of siRNA knockdown of CYP2B1 and effects on retinoid signaling. a, b siRNA-transfected cells showed reduction in CYP26B1 gene expression. Results are shown as means \pm SEM, $\mathrm{n}=5$, assayed by pRARE-TA-SEAP (a) and pSEAP-Basic (b). ${ }^{* *} \mathrm{p}<0.001$ versus control after atRA exposure for 24 h. c, d Retinoid signaling was assayed by using a cell-based reporter pRARE-TA-SEAP (c) and pSEAP-Basic (d). Results are shown as means $\pm \mathrm{SEM}, \mathrm{n}=5$. ${ }^{* * *} \mathrm{p}<0.001$ versus control after atRA exposure for $24 \mathrm{~h}$. No differences were observed in cells transfected by pSEAP-Basic (Student's t test).
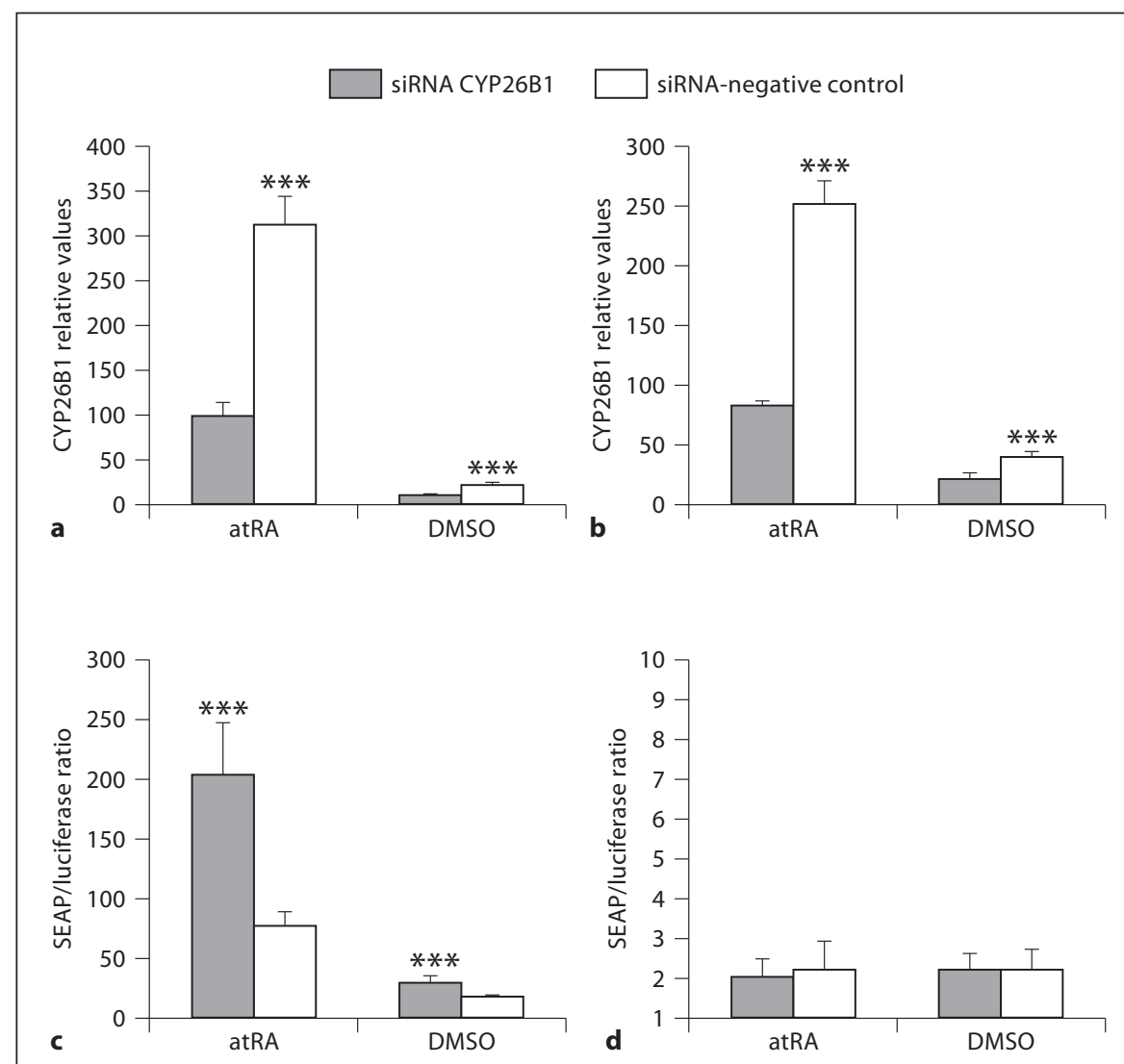

AOSMCs with this method (data not shown). Moreover, whereas the expression of CYP26C1 was barely detectable in Hepg 2 cells, stimulation of these cells with atRA $(1 \mu \mathrm{mol} / \mathrm{l})$ for $24 \mathrm{~h}$ significantly induced CYP26A1 mRNA $(\mathrm{n}=4, \mathrm{p}<0.001)$ and had only modest effects on the expression of CYP26B1 (data not shown).

\section{Effects of siRNA Knockdown of CYP26B1 on Retinoid}

Signaling in AOSMCs

To investigate the importance of CYP26B1 on retinoid signaling, AOSMCs were transfected with siRNA for CYP26B1. CYP26B1 siRNA decreased the levels of CYP26B1 mRNA by approximately $65 \%$ compared to control siRNA-transfected cells after $24 \mathrm{~h}$ of atRA exposure (fig. 2a, b). Retinoid signaling activity was monitored by using a cell-based reporter, i.e. the pRARE-TA-SEAP assay. In this system, a secreted alkaline phosphatase reporter gene carries a RARE promoter, which is activated in the presence of atRA through the binding of the ligand-activated receptors RAR and RXR. Results were similar regardless of the reporter system (pRARE-TA-
SEAP or pSEAP-Basic; fig. 2a, b). Levels of CYP26B1 in cells unexposed to atRA but transfected with CYP26B1 siRNA were also reduced (fig. $2 a, b$ ). The reduction of CYP26B1 mRNA (fig. 2a, b) was associated with increased levels of RARE-regulated secreted alkaline phosphatase activity (fig. 2c, d). In pSEAP-Basic control, CYP26B1 knockdown did not affect secreted alkaline phosphatase activity (fig. 2d).

\section{Effects of R115866 on Retinoid Metabolism}

To further study the role of CYP26 enzymes on retinoid uptake and metabolism, AOSMCs were incubated with radioactively labeled retinoids $\left(\left[{ }^{3} \mathrm{H}\right] \mathrm{RA}\right.$ or $\left.\left[{ }^{3} \mathrm{H}\right] \mathrm{ROH}\right)$ in the presence or absence of $1 \mu \mathrm{mol} / \mathrm{l}$ of the CYP26 inhibitor R115866. The cellular levels of $\left[{ }^{3} \mathrm{H}\right] \mathrm{RA}$ after 6 - and 24-hour incubations were then determined by high-performance liquid chromatography.

Inhibition of CYP26 enzymes by R115866 $4 \mathrm{~h}$ prior to the addition of $\left[{ }^{3} \mathrm{H}\right] \mathrm{RA}$ significantly increased the cellular content of $\left[{ }^{3} \mathrm{H}\right] \mathrm{RA}$ after 6 and $24 \mathrm{~h}$ of incubation (fig. 3a). Inhibition of the CYP26 family of enzymes with 


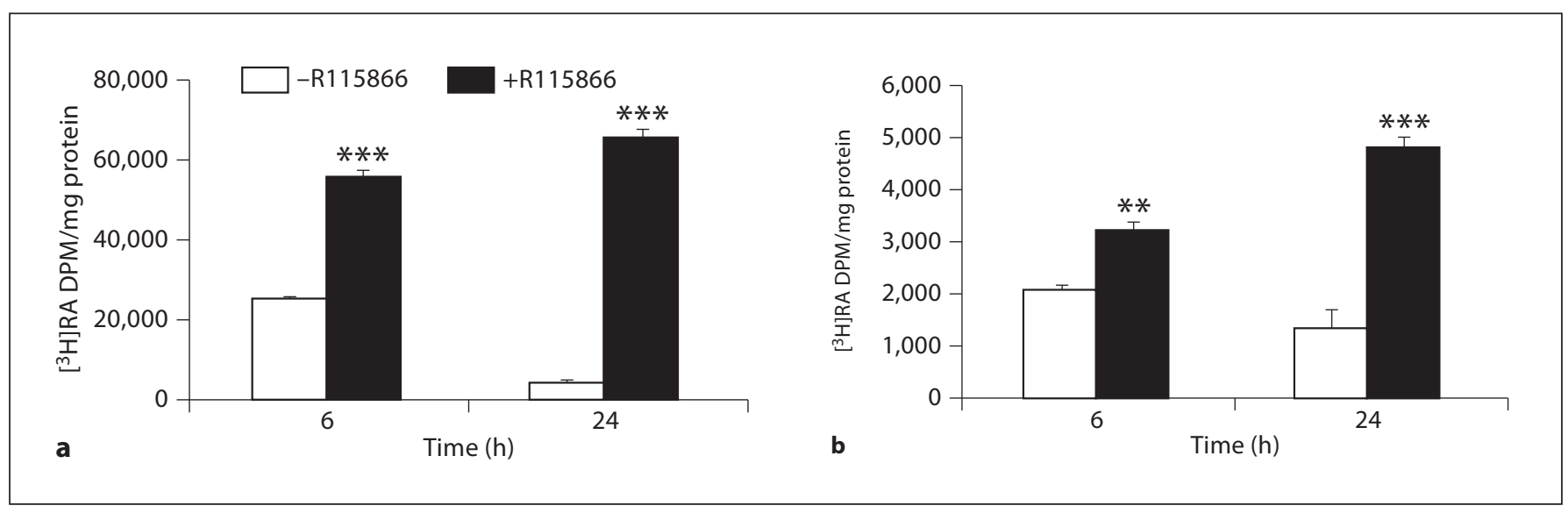

Fig. 3. R115866 increased cellular levels of retinoic acid. The cellular levels of $\left[{ }^{3} \mathrm{H}\right] \mathrm{RA}$ in AOSMCs were measured by using highperformance liquid chromatography. Effects of the CYP26 inhibitor R115866 (1 $\mu \mathrm{mol} / \mathrm{l})$ on cellular atRA levels after incubation with $\left[{ }^{3} \mathrm{H}\right] \mathrm{RA}$ (a) alone $\square$ (-R115866) or in combination with the CYP26 inhibitor $\square$ (+R115866) or with $\left[{ }^{3} \mathrm{H}\right] \mathrm{ROH}$ (b) alone $\square$ (-R115866) or in combination with inhibitor $\quad(+\mathrm{R} 115866)$. Values are shown as means \pm SEM, $n=3 .{ }^{* *} \mathrm{p}<0.01,{ }^{* * *} \mathrm{p}<0.001$ as determined by Student's t test.
R115866 $4 \mathrm{~h}$ prior to the addition of $\left[{ }^{3} \mathrm{H}\right] \mathrm{ROH}$ resulted in a significant increase in formed $\left[{ }^{3} \mathrm{H}\right] \mathrm{RA}$ cellular levels (fig. 3b).

\section{Inhibition of CYP26 Induced atRA-Responsive Genes}

Since we demonstrated expression of CYP26 in AOSMCs, and also that inhibition of CYP26-mediated atRA catabolism increased cellular levels of at RA, we investigated the effect of CYP26 inhibition on the mRNA expression of atRA-responsive genes. AOSMCs were incubated with $1 \mu \mathrm{mol} / \mathrm{l}$ of R115866 for 8-72 h after which the expression of CYP26B1 and RAR- $\beta$ was analyzed using real-time RT-PCR. CYP26B1 mRNA was significantly induced by R115866 at all time points (fig. 4a). R115866 also led to a significant induction of the mRNA expression of RAR- $\beta$ after $24-72$ h (fig. $4 \mathrm{~b}$ ). Cells were, furthermore, incubated with R115866 (0.01-10 $\mu \mathrm{mol} / \mathrm{l})$ for $48 \mathrm{~h}$ and analyzed for mRNA levels of CYP26B1 and RAR- $\beta$. The expression of CYP26B1 (fig. 4c) and RAR- $\beta$ (fig. $4 \mathrm{~d}$ ) was significantly induced in a dose-dependent manner.

\section{R115866-Inhibited DNA Synthesis and Cell \\ Proliferation}

We were then interested to investigate the effects of CYP26 inhibition on proliferation. AOSMCs were incubated with R115866 (1, 5, 10 and $15 \mu \mathrm{mol} / \mathrm{l})$ for $120 \mathrm{~h}$, and this exposure inhibited DNA synthesis in a dose-dependent manner (fig. 5a). The $\mathrm{IC}_{50}$ for $\mathrm{R} 115866$ was
8.1 $\mu \mathrm{mol} / \mathrm{l}$. Stimulation of AOSMCs with $5 \mu \mathrm{mol} / \mathrm{l}$ of R115866 for 24-120 h significantly inhibited DNA synthesis in AOSMCs at all time points (fig. $5 b$ ).

Also, $15 \mu \mathrm{mol} / \mathrm{l} \mathrm{R} 115866$ for $72 \mathrm{~h}$ significantly inhibited AOSMC proliferation, with $21.3 \pm 1$ versus $31.2 \pm$ 1 ratio of harvested cell count to the number of seeded cells $(n=6, p=0.0001)$. To investigate whether these effects on DNA synthesis were RAR mediated, we coincubated the cells with $1 \mu \mathrm{mol} / \mathrm{l}$ of the RAR antagonist CD3106 or R115866 for $120 \mathrm{~h}$. R115866 alone significantly reduced proliferation $(89 \pm 2$ vs. $100 \pm 1 \%$ of control, $\mathrm{n}=4, \mathrm{p}=0.004)$. This reduction was significantly blocked by coincubation with CD3106 (89 \pm 2 vs. $96 \pm 1 \%$ of control, $\mathrm{n}=4, \mathrm{p}=0.01$ ).

Next, we studied the effects of CYP26 inhibition in combination with atRA treatment on DNA synthesis in AOSMCs. AOSMCs were stimulated with atRA (0.0005$5 \mu \mathrm{mol} / \mathrm{l})$ in the presence or absence of R115866 ( $1 \mu \mathrm{mol} / \mathrm{l})$ for $120 \mathrm{~h}$. atRA alone significantly inhibited DNA synthesis in a dose-dependent manner (fig. 5c). Inhibition of the CYP26 enzymes before atRA administration significantly enhanced the inhibitory effects of atRA on DNA synthesis at atRA concentrations of $0.005-0.05 \mu \mathrm{mol} / \mathrm{l}$ (fig. $5 \mathrm{c}$ ). The calculated $\mathrm{IC}_{50}$ value for atRA in combination with R115866 was lower than that of atRA alone $\left(6.3 \times 10^{-3}\right.$ vs. $7.4 \times 10^{-3} \mu \mathrm{mol} / \mathrm{l}$, respectively), but the difference was not statistically significant. 


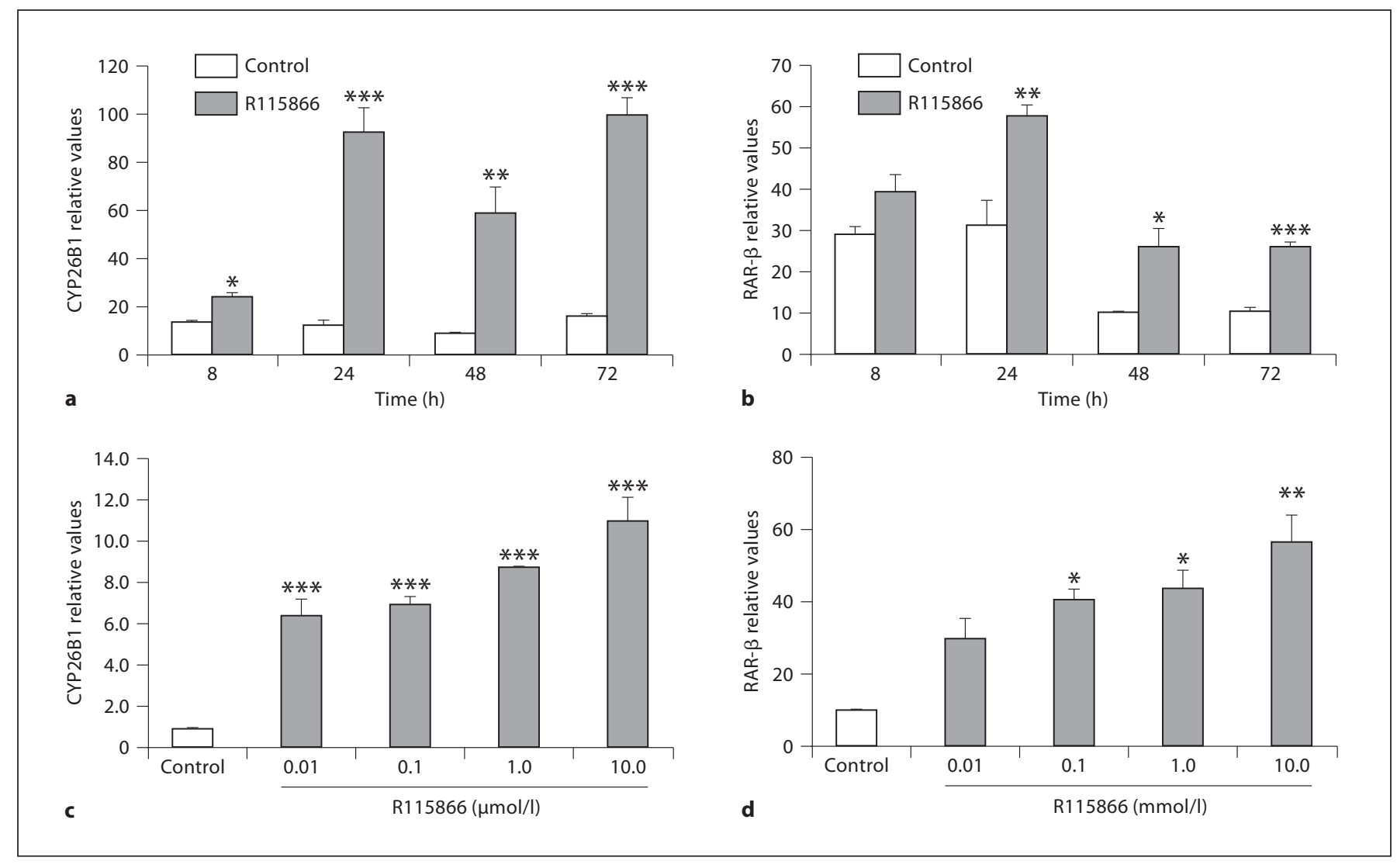

Fig. 4. Effects of R115866 on CYP26B1 and RAR- $\beta$ mRNA expression in AOSMCs. mRNA expression of CYP26B1 (a) and RAR- $\beta$ (b) in AOSMCs after stimulation with $1 \mu \mathrm{mol} / \mathrm{l}$ of R115866 for 8-72 h. mRNA expression of CYP26B1 (c) and RAR$\beta$ (d) after stimulation with $0.001-10.0 \mu \mathrm{mol} / \mathrm{l}$ of R115866 for
$48 \mathrm{~h}$. Levels of CYP26B1 and RAR- $\beta$ were normalized to $\beta$-actin. Values are shown as means \pm SEM, $\mathrm{n}=3 .{ }^{*} \mathrm{p}<0.05,{ }^{* *} \mathrm{p}<0.01$, ${ }^{* * *} \mathrm{p}<0.001$, treatment versus control (Student's t test, $\mathbf{a}, \mathbf{b}$; oneway ANOVA with Dunnett's adjustment, c, d).

\section{Discussion}

In this study, we show that CYP26B1 is the predominantly expressed CYP26 enzyme in human AOSMCs and that inhibition of the CYP26 family enzymes or CYP26B1 alone results in increased retinoid signaling. Using a potent inhibitor of CYP26, R115866, we demonstrated that inhibition of this family of enzymes decreased retinoid clearance in AOSMCs, which resulted in retinoidal effects, i.e. induction of gene expression and inhibition of cellular proliferation. Specific knockdown of CYP26B1 levels by using siRNA increased retinoid signaling. Furthermore, CYP26B1 mRNA in AOSMCs was induced by atRA. This induction suggests a negative feedback loop in which atRA induces its inactivation and by which these cells regulate their retinoid levels, a notion supported also by data from cell lines $[23,29,30]$.
The therapeutic potential of retinoids in vascular diseases has been demonstrated in several studies using different animal models. Retinoids have been shown to reduce neointimal thickening [7-9], through both inhibition of cellular proliferation $[9,31]$ and promotion of apoptosis [32]. However, the ability of atRA to accelerate its inactivation by inducing cytochrome $\mathrm{P} 450$ activity, as has been implicated in acquired retinoid resistance during atRA treatment of acute promyelocytic leukemia [33, 34], may limit the effectiveness of retinoids. Therefore, our results showing that inhibition of CYP26 and more specifically, CYP26B1, increases retinoid signaling in human vascular cells adds new insight into the role of CYP26 in vascular cells and suggests a potential novel way to circumvent the development of retinoid resistance. The effects of R115866 on retinoid catabolism in AOSMCs demonstrated in this study are in agreement 


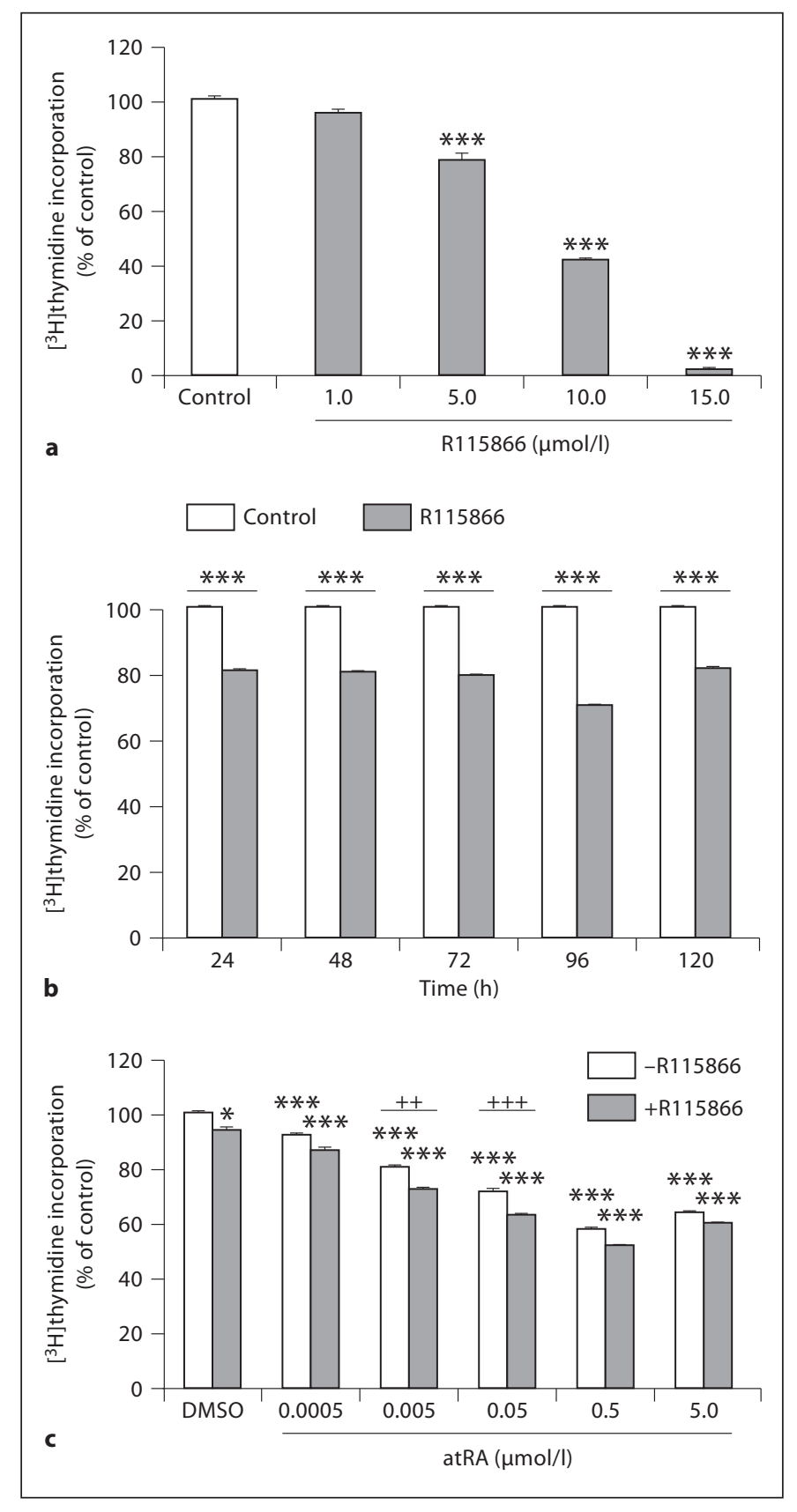

Fig. 5. Effects of R115866 and atRA on DNA synthesis in AOSMCs. a DNA synthesis in AOSMCs after exposure to 1$15 \mu \mathrm{mol} / \mathrm{l} \mathrm{R} 115866$ for $120 \mathrm{~h}$. b Time-dependent effects of R115866 (5 $\mu \mathrm{mol} / \mathrm{l})$ on DNA synthesis. c Dose-dependent effects of atRA alone or in combination with R115866 ( $1 \mu \mathrm{mol} / \mathrm{l})$ on DNA synthesis in AOSMCs after $120 \mathrm{~h}$ of incubation. Data represent means \pm SEM for each condition, $n=4$. $\mathbf{a}, \mathbf{b}^{* * *} \mathrm{p}<0.001$ versus control (-R115866), determined by one-way ANOVA with Dunnett's adjustment (a) or Student's t test (b). $\mathbf{c}^{*} \mathrm{p}<0.05,{ }^{* *} \mathrm{p}<$ 0.001 , treatment (R115866 or atRA in combination with R115866) versus control (DMSO or atRA alone); ${ }^{++} \mathrm{p}<0.01,{ }^{+++} \mathrm{p}<0.001$ atRA alone versus atRA combined with R115866, determined by one-way ANOVA with Bonferroni's adjustment. with our previous study in rat-derived intimal SMCs [27]. Interestingly, whereas retinoid levels in rat intimal SMCs were declining $24 \mathrm{~h}$ after R115866 stimuli [27], this decrease in cellular retinoic acid levels was not observed in AOSMCs. The increased retinoic acid degradation in rat intimal SMCs may reflect a stronger and faster CYP26 induction in these cells compared to human AOSMCs.

R115866 in combination with atRA enhanced the effects of atRA alone on DNA synthesis. This enhancement was only observed at lower and not higher atRA concentrations. The capacity of CYP26 to metabolize atRA is probably exceeded at higher atRA concentrations, resulting in absence of R115866 effects. To test whether the effect of R15866 on AOSMC DNA synthesis was mediated by RARs, cells were coincubated with the pan-RAR antagonist CD3106. The R115866-induced inhibition of cell proliferation was blocked by $\mathrm{CD} 3106$, indicating that the effects of R115866 are at least partly mediated by RARs. Our results support the notion of CYP26 involvement in acquired retinoid resistance, and demonstrate the possibility of enhancing atRA effects in human AOSMCs by blocking its CYP26-mediated catabolism.

Using animal models of atherosclerosis and restenosis, administration of exogenous retinoids was shown to reduce atherosclerosis development in apolipoprotein-Edeficient mice [14] and to inhibit neointimal formation after vessel injury $[7-9,12]$. These studies underscore the therapeutic potentials of retinoids in vascular diseases. However, the fact that atRA induces its inactivation highlights the necessity for alternative approaches. Elevated retinoid levels and the resulting increase in retinoid signaling in AOSMCs after CYP26 inhibition implicate CYP26 in the regulation of atRA levels in human vascular cells and thus suggest an alternative to exogenous retinoid administration.

In conclusion, we show that CYP26B1 is an important regulator of retinoid levels in human AOSMCs. CYP26B1 expression is induced by atRA, and silencing of CYP26B1 by siRNA leads to increased retinoid signaling in AOSMCs. Moreover, inhibition of the CYP26 family results in increased retinoic acid levels and subsequently increases retinoid signaling. Our results suggest that CYP26 inhibitors may provide an alternative to exogenous retinoid administration.

\section{Acknowledgments}

The study was supported by grants from the Swedish Medical Research Council (K2002-71X-02042-36A), the Swedish Heart Lung Foundation and Bergwalls Foundation. 


\section{References}

$\nabla_{1}$ Lai L, Bohnsack BL, Niederreither K, Hirschi KK: Retinoic acid regulates endothelial cell proliferation during vasculogenesis. Development 2003;130:6465-6474.

$\checkmark 2$ Blomhoff R, Blomhoff HK: Overview of retinoid metabolism and function. J Neurobiol 2006;66:606-630.

>3 Niles RM: Vitamin A (retinoids) regulation of mouse melanoma growth and differentiation. J Nutr 2003;133:282S-286S.

$\checkmark 4$ Jimenez-Lara AM, Clarke N, Altucci L, Gronemeyer H: Retinoic-acid-induced apoptosis in leukemia cells. Trends Mol Med 2004;10:508-515.

7 Means AL, Gudas LJ: The roles of retinoids in vertebrate development. Annu Rev Biochem 1995;64:201-233.

-6 Owens GK, Kumar MS, Wamhoff BR: Molecular regulation of vascular smooth muscle cell differentiation in development and disease. Physiol Rev 2004;84:767-801.

7 Miano JM, Kelly LA, Artacho CA, Nuckolls TA, Piantedosi R, Blaner WS: All-trans-retinoic acid reduces neointimal formation and promotes favorable geometric remodeling of the rat carotid artery after balloon withdrawal injury. Circulation 1998;98:1219 1227.

$\checkmark 8$ Chen J, He B, Zheng D, Zhang S, Liu J, Zhu S: All-trans-retinoic acid reduces intimal thickening after balloon angioplasty in atherosclerotic rabbits. Chin Med J (Engl) 1999; 112:121-123.

-9 Neuville P, Yan Z, Gidlof A, Pepper MS, Hansson GK, Gabbiani G, et al: Retinoic acid regulates arterial smooth muscle cell proliferation and phenotypic features in vivo and in vitro through a RARalpha-dependent signaling pathway. Arterioscler Thromb Vasc Biol 1999; 19:1430-1436.

- 10 De Rose JJ Jr, Madigan J, Umana JP, Prystowsky JH, Nowygrod R, Oz MC, et al: Retinoic acid suppresses intimal hyperplasia and prevents vessel remodeling following arterial injury. Cardiovasc Surg 1999;7:633-639.

-11 Lee CW, Park SJ, Park SW, Kim JJ, Hong MK, Song JK: All-trans-retinoic acid attenuates neointima formation with acceleration of reendothelialization in balloon-injured rat aorta. J Korean Med Sci 2000;15:31-36.

-12 Wiegman PJ, Barry WL, McPherson JA, McNamara CA, Gimple LW, Sanders JM, et al: All-trans-retinoic acid limits restenosis after balloon angioplasty in the focally atherosclerotic rabbit: a favorable effect on vessel remodeling. Arterioscler Thromb Vasc Biol 2000;20:89-95
13 Wuttge DM, Romert A, Eriksson U, Torma H, Hansson GK, Sirsjo A: Induction of CD36 by all-trans-retinoic acid: retinoic acid receptor signaling in the pathogenesis of atherosclerosis. Faseb J 2001;15:1221-1223.

14 Takeda N, Manabe I, Shindo T, Iwata H, Iimuro S, Kagechika H, et al: Synthetic retinoid Am80 reduces scavenger receptor expression and atherosclerosis in mice by inhibiting IL-6. Arterioscler Thromb Vasc Biol 2006;26:1177-1183.

15 Napoli JL: Interactions of retinoid binding proteins and enzymes in retinoid metabolism. Biochim Biophys Acta 1999;1440:139162.

16 Napoli JL: Retinoic acid biosynthesis and metabolism. Faseb J 1996;10:993-1001.

17 Leo MA, Lasker JM, Raucy JL, Kim CI, Black M, Lieber CS: Metabolism of retinol and retinoic acid by human liver cytochrome P450IIC8. Arch Biochem Biophys 1989;269:305312.

18 Nadin L, Murray M: Participation of CYP2C8 in retinoic acid 4-hydroxylation in human hepatic microsomes. Biochem Pharmacol 1999;58:1201-1208.

19 McSorley LC, Daly AK: Identification of human cytochrome $\mathrm{P} 450$ isoforms that contribute to all-trans-retinoic acid 4-hydroxylation. Biochem Pharmacol 2000;60:517-526.

20 White JA, Beckett-Jones B, Guo YD, Dilworth FJ, Bonasoro J, Jones G, et al: cDNA cloning of human retinoic acid-metabolizing enzyme (hP450RAI) identifies a novel family of cytochromes P450. J Biol Chem 1997;272:18538-18541.

21 White JA, Ramshaw H, Taimi M, Stangle W Zhang A, Everingham S, et al: Identification of the human cytochrome P450, P450RAI-2, which is predominantly expressed in the adult cerebellum and is responsible for alltrans-retinoic acid metabolism. Proc Natl Acad Sci USA 2000;97:6403-6408.

-22 Taimi M, Helvig C, Wisniewski J, Ramshaw H, White J, Amad M, et al: A novel human cytochrome P450, CYP26C1, involved in metabolism of 9-cis and all-trans isomers of retinoic acid. J Biol Chem 2004;279:77-85.

23 Ray WJ, Bain G, Yao M, Gottlieb DI: CYP26, a novel mammalian cytochrome $\mathrm{P} 450$, is induced by retinoic acid and defines a new family. J Biol Chem 1997;272:18702-18708.

24 Muindi J, Frankel SR, Miller WH Jr, Jakubowski A, Scheinberg DA, Young CW, et al: Continuous treatment with all-trans-retinoic acid causes a progressive reduction in plasma drug concentrations: implications for relapse and retinoid 'resistance' in patients with acute promyelocytic leukemia. Blood 1992;79:299-303.
25 Njar VC, Gediya L, Purushottamachar P, Chopra P, Vasaitis TS, Khandelwal A, et al: Retinoic acid metabolism blocking agents (RAMBAs) for treatment of cancer and dermatological diseases. Bioorg Med Chem 2006; 14:4323-4340.

26 Stoppie P, Borgers M, Borghgraef P, Dillen L, Goossens J, Sanz G, et al: R115866 inhibits all-trans-retinoic acid metabolism and exerts retinoidal effects in rodents. J Pharmacol Exp Ther 2000;293:304-312.

$>27$ Ocaya P, Gidlof AC, Olofsson PS, Torma H, Sirsjo A: CYP26 inhibitor R115866 increases retinoid signaling in intimal smooth muscle cells. Arterioscler Thromb Vasc Biol 2007;27: 1542-1548.

28 Gidlof AC, Ocaya P, Olofsson PS, Torma H, Sirsjo A: Differences in retinol metabolism and proliferative response between neointimal and medial smooth muscle cells. J Vasc Res 2006;43:392-398.

-29 Abu-Abed SS, Beckett BR, Chiba H, Chithalen JV, Jones G, Metzger D, et al: Mouse P450RAI (CYP26) expression and retinoic acid-inducible retinoic acid metabolism in F9 cells are regulated by retinoic acid receptor gamma and retinoid $\mathrm{X}$ receptor alpha. J Biol Chem 1998;273:2409-2415.

30 Sonneveld E, van den Brink CE, van der Leede BM, Schulkes RK, Petkovich M, van der Burg B, et al: Human retinoic acid (RA) 4-hydroxylase (CYP26) is highly specific for all-trans-RA and can be induced through $\mathrm{RA}$ receptors in human breast and colon carcinoma cells. Cell Growth Differ 1998;9: 629-637.

31 Miano JM, Topouzis S, Majesky MW, Olson EN: Retinoid receptor expression and alltrans-retinoic acid-mediated growth inhibition in vascular smooth muscle cells. Circulation 1996;93:1886-1895.

32 Orlandi A, Francesconi A, Cocchia D, Corsini A, Spagnoli LG: Phenotypic heterogeneity influences apoptotic susceptibility to retinoic acid and cis-platinum of rat arterial smooth muscle cells in vitro: implications for the evolution of experimental intimal thickening. Arterioscler Thromb Vasc Biol 2001; 21:1118-1123.

33 Warrell RP Jr: Retinoid resistance in acute promyelocytic leukemia: new mechanisms, strategies, and implications. Blood 1993;82: 1949-1953.

34 Osanai M, Petkovich M: Expression of the retinoic acid-metabolizing enzyme CYP26A1 limits programmed cell death. Mol Pharmacol 2005;67:1808-1817. 